\title{
Intracranial germ-cell tumor with synchronous lesions in the pineal and suprasellar regions: A rare case of hypopituitarism
}

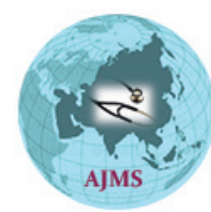

\author{
Kaushik Ghosh ${ }^{1}$, Paromita Bhattacharya ${ }^{2}$, Muhammed Imran Ahmad Quereshi ${ }^{3}$, \\ Sarmistha Mukhopadhyay ${ }^{4}$, Ambarish Bhattacharya ${ }^{5}$
}

\begin{abstract}
${ }^{1}$ Associate Professor, Department of Medicine, Murshidabad Medical College and Hospital, Berhampore, ${ }^{2}$ Assistant Professor, Department of Medicine, Chittaranjan National Medical College, Kolkata, West Bengal, India, ${ }^{3}$ Consultant, Department of Acute Medicine, Worcestershire Acute Hospitals NHS Trust, Worcester, England, United Kingdom, ${ }^{4}$ Physician and Endocrinologist, Department of Medicine and Endocrinology, BR Singh Hospital, ${ }^{5}$ Visiting Consultant, Department of Medicine, Charnock Hospital, Kolkata, West Bengal, India
\end{abstract}

Germinomas represent the most frequent tumor type in the pineal region and the synchronous involvement in the suprasellar region, known as bifocal disease, is increasingly recognized. Synchronous primary intracranial germ cell tumors are rare. Among all germ cell tumors, only $5-10 \%$ are found as synchronous lesions in pineal and suprasellar regions. They are also known by the entity "double mid-line atypical teratoma." An adolescent male with phenotypic features of delayed puberty presents with features of hypopituitarism and raised intracranial tension. He was subsequently treated with hormonal replacement and diagnosed as a case of bifocal intracranial germinoma. Interestingly, he was lacking features of diabetes insipidus, which is a conspicuous feature in other reported cases. He was treated further with ventricular shunting followed by cranio spinal irradiation. The complex nature of endocrinological manifestations in bifocal intracranial germinoma will enriches our knowledge toward a potentially curable neuroendocrinological situation.

Key words: Hypopituitarism; Intracranial germinoma; Synchronous lesions

\section{Access this article online}

Website:

http://nepjol.info/index.php/AJMS DOI: 10.3126/ajms.v13i3.41976

E-ISSN: 2091-0576

P-ISSN: 2467-9100

Copyright (c) 2022 Asian Journal of Medical Sciences

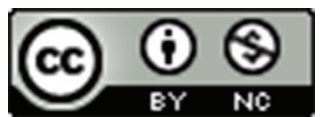

This work is licensed under a Creative Commons Attribution-NonCommercial 4.0 International License.

\section{INTRODUCTION}

Germinomas account for halves of the pineal gland tumors and most prevalent primary intracranial neoplasms. They account for $2-5 \%$ of the central nervous system (CNS) malignancies in Western countries. ${ }^{1}$ The most of the patients present in early second decades with varied neurological presentations. Intracranial germinomas have special predilections for male gender during puberty suggesting a hormonal influence. , $^{2,3}$ Histologically, the pure germ cell tumor accounts for up to $60 \%$ of intracranial subtype and has special predilections for midline structures. The pineal and suprasellar regions are most commonly involved, whereas synchronous bifocal involvement occurs in 10\% of all intracranial germ cell tumors (GCTs). ${ }^{4,5}$ When they affect the pineal region, then patients present with neurological manifestations of raised intracranial tension due to obstruction of cerebral aqueduct. ${ }^{6}$ Bifocal involvement of pineal region, as well as a supra seller region, is being increasingly recognized though overall is a rare entity. Suprasellar involvement manifests endocrinologically and usually becomes presenting features in bifocal or synchronous involvement.

Here, we report an adolescent presented with hypopituitarism and features of delayed puberty that 
subsequently was diagnosed as synchronous intracranial germinoma. After initial neurosurgical shunting to tackle obstructive features, he was successfully treated with craniospinal irradiation and later on hormonal replacement.

\section{CASE REPORT}

A 15-year-old male student attends emergency with altered sensorium for the past $2 \mathrm{~h}$ and gradually worsening headache accompanied with one episode of vomiting. The type of headache was initially dull and non-radiating without any features of neurological deficit. He had a history of headaches which were increasing the intensity gradually and he experienced one episode of vomiting which was a projectile in nature. His medical records were unremarkable for any disease or drug intake, but his parents were anxious for some weight loss for a few months which was attributed to his stress for the upcoming examination. Five to six months before the occurrence of headache, he was a very energetic student. He had a history of loss of appetite for the same duration.

On examination, he presented with striking paleness with dry skin, less developed secondary sexual characters (Tanner Stage 2). Neurological examination revealed a complete right third, fourth, and sixth cranial nerve palsies. The rest of the systemic examination was unremarkable.

On admission, blood pressure was $80 / 40 \mathrm{mmHg}$ with a pulse rate of 100 beats/min and Spo2 was $98 \%$ at room air. His blood glucose level on the strip test was $48 \mathrm{mg} / \mathrm{dl}$. After recording his vitals, he was started immediately with one ampule of D 50.

There was a complete right third cranial nerve palsy along with the right fourth and sixth cranial nerve palsies. Examinations of other systems were unremarkable. Laboratory results on admission revealed mild anemia with hyponatremia $(\mathrm{Na}+108 \mathrm{mmol} / \mathrm{L})$. After initial stabilization with dextrose and intravenous hydrocortisone, the patient was shifted to the intensive care unit and computed tomography (CT) of the brain was performed. CT scan of brain shows (Figure 1) $-47 \mathrm{~mm} \times 44 \mathrm{~mm}$ welldefined mass lesion in the midline at pineal gland region with nodular peripheral calcifications, homogeneous intense enhancement on contrast compressing both $3^{\text {rd }}$ ventricle, dilated both lateral ventricle, cortical sulci effaced, basal cistern, and Sylvian fissure effaced whereas posterior fossa was normal. Endocrinological evaluation was done afterward yields partial insufficiency of the adrenocorticotropic, gonadotropic, and thyroidal axis as well as hyperprolactinemia (Table 1). At this stage, the

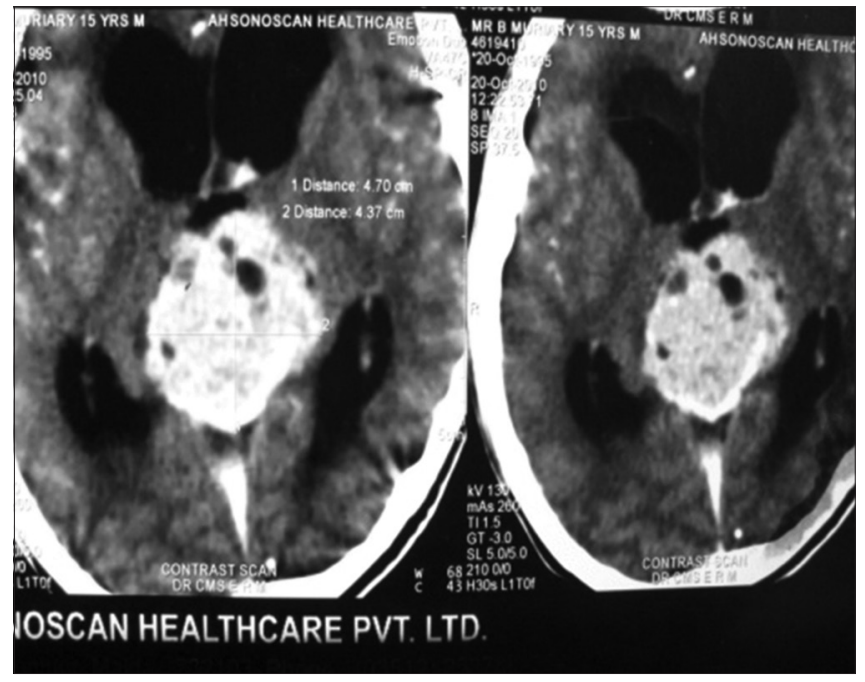

Figure 1: Well-defined mass lesion in the midline at pineal gland region with nodular peripheral calcifications, homogeneous intense enhancement on contrast compressing both third ventricle and dilated both lateral ventricles

\begin{tabular}{|c|c|c|}
\hline Hormonal axis & Results & Normal Range \\
\hline \multicolumn{3}{|l|}{ Adreno cortico tropic axis } \\
\hline Basal cortisol ( $\mu \mathrm{g} / \mathrm{dl})$ & 1.74 & $5-25 \mu \mathrm{g} / \mathrm{dl}$ \\
\hline Basal ACTH (pg/ml) & 4 & $5-60$ \\
\hline $\begin{array}{l}\text { Cortisol after ACTH } \\
\text { stimulation }(\mu \mathrm{g} / \mathrm{dl})\end{array}$ & 14.2 & $>20$ \\
\hline \multicolumn{3}{|l|}{ Thyroid axis } \\
\hline $\mathrm{TSH} \mu \mathrm{U} / \mathrm{ml}$ & 0.056 & $0.34-4.25$ \\
\hline Free thyroxine (ng/dl) & 0.56 & $0.8-1.7 \mathrm{ng} / \mathrm{ml}$ \\
\hline \multicolumn{3}{|l|}{ Gonadotropic axis } \\
\hline FSH (IU/I) & 0.6 & $1-10$ \\
\hline $\mathrm{LH}(\mathrm{IU} / \mathrm{I})$ & 0.4 & $1-10$ \\
\hline Testosterone (ng/dl) & 98 & $350-900$ \\
\hline \multicolumn{3}{|l|}{ Lactotropic axis } \\
\hline Prolactin $\mu \mathrm{g} / \mathrm{dl}$ & 24 & $2-18$ \\
\hline \multicolumn{3}{|l|}{ Somatotropic } \\
\hline IGF $1 \mathrm{ng} / \mathrm{ml}$ & $68 \mathrm{ng} / \mathrm{ml}$ & $132-475 \mathrm{ng} / \mathrm{ml}$ \\
\hline
\end{tabular}

ACTH: Adrenocorticotropic hormone, TSH: Thyroid stimulating hormone, FSH: Follicle-stimulating hormone, LH: Luteinizing hormone, IGF: Insulin-like growth factor-1

provisional diagnosis was intracranial midline enhancing mass lesion associated with hypopituitarism and mass effect on the thirs ventricle. Subsequently, the patient was initiated with steroid followed by oral levothyroxine and later testosterone replacement. Two days after admission patient regained consciousness fully and a dose of hydrocortisone was gradually tapered. Further neurological examination at this stage showed bilateral mild papilledema with restricted upward gaze and failure of convergence. Planters were bilaterally extensor so also exaggerated reflexes. The power of lower limbs was four out of five without any sensory or autonomic manifestations. 
On further evaluation, magnetic resonance imaging (MRI) scan of the head shows large heterogeneously enlarging mass in pineal gland region with calcification within and compressing cerebral aqueduct with obstructive hydrocephalus. Small enhancing mass lesion in pituitary fossa (Figure 2). No metastasis was noted on the MRI scan along the craniovertebral axis. Sr. Serum alpha-fetoprotein (AFP) and beta-human chorionic gonadotropin (B-HCG) were measured in the normal range $(<0.605 \mathrm{IU} / \mathrm{L}$ and 3.64 IU/L, respectively).

Evaluation of cerebro spinal fluids results was normal including cerebrospinal fluid (CSF) B-HCG and AFP$(\beta$-hCG concentration in CSF: $<0.4 \mathrm{IU} / \mathrm{L}$; and AFP in CSF: $<53.2 \mathrm{IU} / \mathrm{L})$.

He was treated by the neurosurgical team, had an endoscopic biopsy of the pineal tumor, and a right ventriculoperitoneal shunt was performed. Histopathology report showed sheets of large cells having a round vesicular nucleus, prominent nucleoli, and vacuolated cytoplasm. Mitotic activity was prominent. Lymphocyte aggregates were seen surrounding the tumor cells confirming the diagnosis of germinoma (Figure 3).

The patient showed excellent recovery after the operation though mild ataxia persisted on the past follow-up. He underwent radiotherapy with craniospinal irradiation covering the entire CNS according to the protocol. Thereafter, he was advised for replacement with hydrocortisone, levothyroxine, and parenteral testosterone therapy.

\section{DISCUSSION}

The origin of a GCT remains unclear with several controversies. This malignant tumor originates from primordial germ cells which have migrated from yolk sac developments. ${ }^{6.7}$ The most common age of presentation is the first and second decade of life with male predominance. ${ }^{3}$ The World Health Organization classifies CNS GCTs histologically into the following groups, Germinoma - Pure and with syncytiotrophoblast, non-germinomatous GCTs, teratoma, embryonal carcinoma, Yolk sac tumor or endodermal sinus tumor, and choriocarcinoma. ${ }^{8}$

Pure germinoma accounts for $65 \%$ of all CNS GCTs and is predominantly found in midline structure where their migration is arrested during fetal development. Intracranial GCTs express germ cell-specific proteins such as MAGE-A4, NY-ESO-1, and TSPY which indicate primordial germ cell origin. Individuals with Klinefelter syndrome (47 XXY Genotype), down syndrome, and
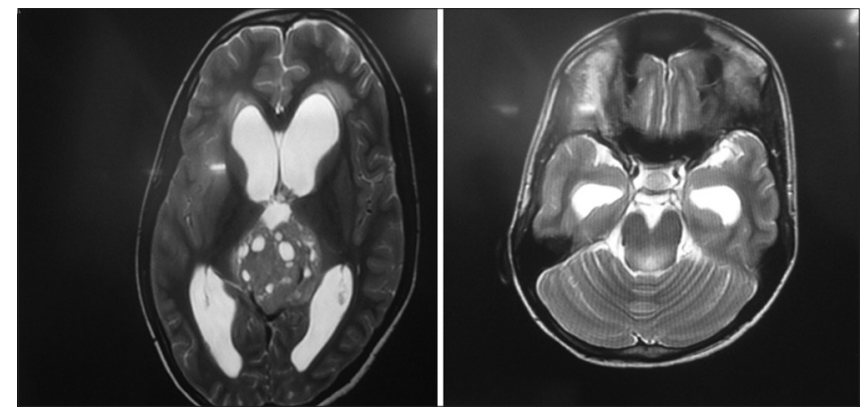

Figure 2: Magnetic resonance imaging scan of the head shows large heterogeneously enlarging mass in pineal gland region with calcification within and compressing cerebral aqueduct with obstructive hydrocephalus. Small enhancing mass lesion in pituitary fossa

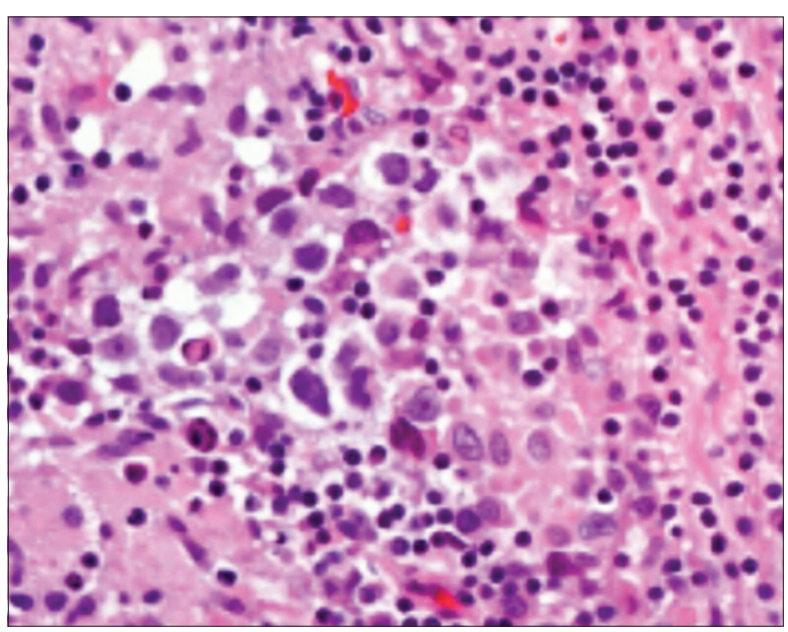

Figure 3: Sheets of large cells having round vesicular nucleus, prominent nucleoli, and vacuolated cytoplasm, prominent mitotic activity. Lymphocyte aggregates are also seen surrounding the tumor cells confirming the diagnosis of germinoma

neurofibromatosis type 1 are susceptible to developing intracranial GCTs. Alterations of the p14 gene and mutations of the c-kit gene have been found in a sizeable number of intracranial germinoma patients. Up to 185 patients of intracranial GCT showed the synchronous involvement of pineal as well as suprasellar involvement. Our patient was suffering from large germinoma encroaching lateral ventricle apart from midline structures. As there was more than midline structure involved in our case, metastasis has to be excluded with further cranio axial neurological imaging studies. The frequent seed of tumor in ventricles and CSFs is, in general, agreement of metastasis which however was not presented in this case.

Site, size, and behavior, as well as age mainly determine clinical behavior as in most of the other intracranial tumors. As a general rule, pineal lesions being commonly involved, mostly present with neurological symptoms. Obstruction of cerebral aqueduct results in increased intracranial pressure and manifested with a headache, diplopia, vomiting, or papilledema., ${ }^{6,9}$ Our patient was 
suffering from features of raised intracranial pressure for a considerable duration before an endocrinological emergency develops. Involvement of the suprasellar region disrupts the hypothalamic-pituitary axis. Interestingly, features of the central diabetes insipidus were absent in this case which is otherwise a common association. This supports the varied endocrinological presentation of a complex intracranial tumor. Synchronous germinoma tends to present with endocrinological manifestations as the suprasellar region was an enclosed space and tumor reaches a critical mass. Delayed puberty, low testicular volume scanty secondary sexual characteristics, in this case, supports the possibility of long standing nature of intracranial germinoma.

Theoretically, total surgical resection of the tumor is the gold standard treatment, which is frequently hampered due to the deep-seated nature of the CNS GCT. Therefore, craniospinal irradiation stands as the treatment of choice in most of the cases. A late sequel of neurocranial irradiation often manifests as significant morbidity and should be taken into account when treatment protocol is to be planed. ${ }^{6,10}$

A complete remission with a 5 -year survival of more than $90 \%$ has been achieved with radiotherapy alone in the case of CNS germinoma. ${ }^{10}$ The role of chemotherapy is controversial and large prospective data are needed to draw a conclusion.

\section{CONCLUSION}

The complex nature of endocrinological manifestations in bifocal intracranial germinoma is challenging and attending physician must be equiped with the essential knowledge to arrive a diagnosis.

\section{ACKNOWLEDGMENTS}

The authors acknowledge constant help of Professor Udas Chandra Ghosh and Dr Susmita Ghosh and also family member of the patient to share this experience for medical community.

\section{REFERENCES}

1. Aoyama H. Induction chemotherapy followed by low-dose involved-field radiotherapy for intracranial germ cell tumors. J Clin Oncol. 2002;20(3):857-865.

https://doi.org/10.1200/JCO.2002.20.3.857

2. Segretain, D. Endocytic activity of male germ cells during puberty. Biol Cell. 1993;78(3):199-205. https://doi.org/10.1016/0248-4900(93)90130-7

3. Capra M, Hargrave D, Bartels U, Hyder D, Huang A and Bouffet E. Central nervous system tumours in adolescents. Eur J Cancer. 2003;39(18):2643-2650. https://doi.org/10.1016/j.ejca.2003.09.003

4. Jennings $M$, Gelman $R$ and Hochberg F. Intracranial germcell tumors: Natural history and pathogenesis. J Neurosurg. 1985;63(2):155-167.

https://doi.org/10.3171/jns.1985.63.2.0155

5. Gabrovski S. Germ-cell tumors of the brain their course and management. Khirurgiia. 1997;50(6):8-15.

https://doi.org/10.1590/S0004-282X2005000500021

6. Janmohamed S, Grossman A, Metcalfe K, Lowe D, Wood D, Chew S, et al. Suprasellar germ cell tumours: Specific problems and the evolution of optimal management with a combined chemoradiotherapy regimen. Clin Endocrinol. 2002;57(4):487-500.

https://doi.org/10.1093/qjmed/hcw052

7. Lee L, Saran F, Hargrave D, Bódi I, Bassi S, and Hortobágyi T. Germinoma with synchronous lesions in the pineal and suprasellar regions. Childs Nerv Syst. 2006;22(12):1513-1518. https://doi.org/10.1016/j.ensci.2019.100187

8. Louis D, Ohgaki H, Wiestler O, Cavenee W, Burger P, Jouvet A, et al. The 2007 WHO classification of tumours of the central nervous system. Acta Neuropathol. 2007;114(2):97-109. https://doi.org/10.1007/s00401-007-0243-4

9. Reisch $\mathrm{N}$, Kühne-Eversmann L, Franke $\mathrm{D}$, Beuschlein $\mathrm{F}$, Mueller-Lisse $U$, Reincke $M$, et al. Intracranial germinoma as a very rare cause of panhypopituitarism in a 23-year old man. Exp Clin Endocrinol Diabetes. 2008;117(07):320-323. https://doi.org/10.1055/s-0028-1100418

10. Maity A, Shu H, Janss A, Belasco J, Rorke L, Phillips P, et al. Craniospinal radiation in the treatment of biopsy-proven intracranial germinomas: Twenty-five years' experience in a single center. Int J Radiat Oncol Biol Phys. 2004;58(4):1165-1170. https://doi.org/10.1016/j.jjrobp.2003.08.028

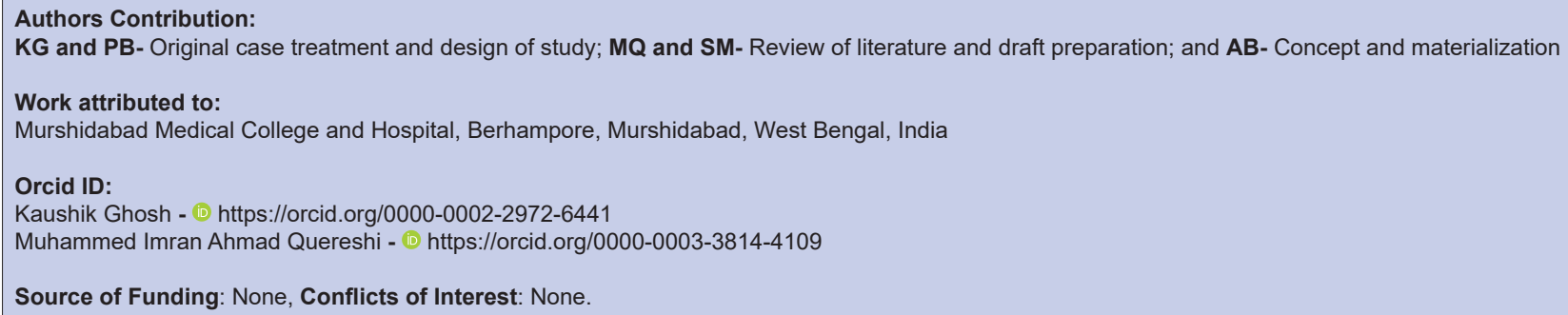

